\title{
Hymen reconstruction as pragmatic empowerment? Results of a qualitative study from Tunisia
}

\author{
Verina Wild, MD, Dr. ${ }^{1}$ \\ Hinda Poulin ${ }^{2}$ \\ Christopher W. McDougall ${ }^{3}$ \\ Andrea Stockl, $\mathrm{PhD}^{4}$ \\ Nikola Biller-Andorno, Prof. Dr. Dr. ${ }^{5}$ \\ ${ }^{5}$ University of Zurich, Switzerland
}

${ }^{1}$ University of Zurich, Switzerland and Ludwig-Maximilians-University Munich, Germany, ${ }^{2}$ EHESS, Paris, France, ${ }^{3}$ University of Toronto, Canada, ${ }^{4}$ University of East Anglia, Great Britain,

Correspondence Address:

Dr. Verina Wild, MD

Institute of Biomedical Ethics and History of Medicine

University of Zurich

Pestalozzistr. 24

8032 Zurich

Switzerland

wild@ethik.uzh.ch

Tel: +41 446348371

Fax: +41446348389

\begin{abstract}
Hymen reconstruction surgery (HR), while ethically controversial, is now available in many countries. Little clinical evidence and hardly any surgical standards support the intervention. Nearly as scarce is social science research exploring women's motivations for the intervention, and health care professionals' justifications for its provision.

In order to better understand decision-making processes, we conducted semi-structured interviews in metropolitan Tunis, in 2009, with six women seeking the procedure, four friends who supported such women, four physicians who perform the operation, and one midwife.

Health care professionals and patient companions expressed moral ambivalence about HR: although they could comprehend the individual situation of the women, they expressed concern that availability of the procedure might further entrench the patriarchal norms that compel the motivation for seeking HR in the first place. Some women seeking HR shared this concern, but felt it was not outweighed by their personal aims, which were to marry and become mothers, or to overcome past violent sexual experiences. The women felt HR to be uniquely helpful in achieving these aims; all made pragmatic decisions about their
\end{abstract}


bodies in a social environment dominated by patriarchal norms. The link between HR and pervasive gender injustice, including the credible threat of serious social and physical harm to women perceived to have failed to uphold the norm of virginity before marriage, raises questions about health care professionals' responsibility while facing requests for HR.

Meaningful regulatory guidance must acknowledge that these genuine harms are at stake; it must do so, however, without resorting to moral double standards. We recommend a reframing of HR as a temporary resource for some women making pragmatic choices in a context of structural gender injustice. We reconfirm the importance of factual sexual and reproductive education, most importantly to counter distorted beliefs that conflate an "intact hymen" with virginity.

Key words: Hymen reconstruction; Hymen repair; Hymenorrhaphy; Gender inequality; Virginity; Ethics; Qualitative study; Tunisia. 


\section{Introduction}

A long-standing cultural expectation in many parts of the world - including the Middle East and North Africa (MENA) region in which our study is set - is that women should enter into marriage as virgins. And an important, if factually incorrect, part of marriage rituals in many religiously conservative traditions is the assumption that all women and girls who have refrained from sexual intercourse have hymens that tear and thus bleed during first sexual intercourse, and that the resulting bloodstains on bedsheets confirm the undefiled state both of a woman's hymen and her virginity (Sissa 1990, Gay-y-Blasco 1997, Steinmueller \& Tan 2015).

The widespread assumption of a correspondence between hymen, virginity, and blood on bed sheets has been called the "the myth of the intact hymen" (Van Moorst et al. 2012:94) because of its biological implausibility: the form taken by the membranous fold of tissue at a woman's vaginal opening varies greatly among individuals, and often wears significantly away during childhood, even in the absence of sexual relations (Adams et al. 2004). Virginity, moreover, is defined differently by different cultures and women, and vaginal sexual penetration cannot be medically or informally ascertained with certainty (Gay-y-Blasco 1997, Boddy 1989). Furthermore, only approximately 50\% of women bleed at first sexual intercourse (Amy 2008). From a biological point of view, a "reconstruction" of the hymen is thus considered to be futile or at least lacking evidence (Juth et al. 2013).

The medical literature on hymen reconstruction (HR) is scarce (Goodman 2011, Braun 2010). Our search initially uncovered just two publications (Ou et al. 2008, Prakash 2009) discussing HR surgical technique, though additional papers have since been published (Wei et al. 2015, Triana \& Robledo 2015). It is thus not possible to reliably assess HR risks, although the limited evidence (e.g. promotional webpages and 
anecdotal reports) suggests that risks are small, with bleeding and minor infections as possible complications.

The moral and social dimensions of HR have just begun to be explored in the literature. Most of the discussion in bioethics has taken the form of brief commentaries focused narrowly on how western physicians should respond to HR requests (e.g. Logmans et al. 1998, Raphael 1998, Amy 2008, Steinmueller \& Tan 2015). Since socially and morally contested norms like those creating demand for HR appear to exploit women's anxieties and promulgate gender injustice, debate is very much unsettled when it comes to understanding individual physician complicity with such norms. This is true not only for hymen reconstruction (Cook and Dickens 2009, Earp 2014) but also for norms that support limitations on women's access to contraception and abortion (Brock 2008), for example, or that promote interventions of questionable benefit, such as genital 'correction' surgery for intersex children (Malmqvist \& Feiler 2010) or aesthetic body alterations (Little 1998). Thus, while some question whether HR should be at all permissible, since it seems likely to further reinforce the subordination of women (Bekker et al. 1996), others view it as comparable to already widely practiced plastic surgeries, and thus as acceptable on the basis of patient autonomy (Logmans et al. 1998). HR has also been interpreted as an empowering form of "multiculturalist action and good feminism" (Saharso 2003: 211; see, also, Ahmadi 2015). Still others reject any suggestion that HR is compatible with feminism, since to claim otherwise gives too much moral weight to individual women seeking $\mathrm{HR}$, at the expense of how their decisions bring harm to other women and "the relevant culture as a whole $[\ldots]$ by reinforcing norms of sex inequality" (Chambers 2004:330). Of note here is how the issues arising from HR are not novel nor geographically nor culturally confined: they raise variations on longstanding debates in feminist philosophy and sociology about embodiment, 
identity, medicalization, and the meaning and consequences of body modification (e.g.: Grosz 1994 and 2005; Bordo 1993; Shildrick \& Price 1998; Butler 1993 and 2004). Indeed, the sexual norms that have led to the demand for HR are not altogether dissimilar to beauty norms underlying cosmetic surgery among Western women (e.g.: McDougall 2013), and both kinds of norms demonstrate that health (and medicine) has social and emotional dimensions that can rival in importance with the biological. HR thus raises a familiar though vexing moral and medical challenge, albeit with distinct socio-cultural contours: how can oppressive social norms be challenged without weakening sympathy for those whom they victimize, and without denying the individual right to make self-regarding medical choices that may be uniquely capable of relieving or preventing certain kinds of suffering, even if those decisions seem to uphold oppressive norms?

Most of the discussion on the moral and social dimensions of HR in the limited empirical literature skirts this challenge, and only a handful of studies have reported data on patient and provider needs and motivations. In fact, a literature search (in MedLine, Google Scholar, and Sociological abstracts, using an expansive list of search terms for HR, up to summer 2014) uncovered only seven empirical studies (Ahmadi 2014, Awwad et al. 2013, Zeyneloğlu et al. 2013, Essén et al. 2010, Tschudin et al. 2013, Van Moorst et al. 2012, Juth et al. 2013, Wild et al. 2010). A few others have recently been published (Steinmueller \& Tan 2014; Loeber 2015). Several of these studies emphasized the need for more research, particularly to explore the needs of both women and health care providers (Essén et al. 2010, Tschudin et al. 2013). There is, however, an overall lack of data drawn directly from women who have undergone the procedure or are contemplating doing so. Only two published studies, both from the Netherlands, employed interviews with women undergoing HR (Van Moorst et al. 2012, Loeber 2015). Van Moorst et al. embedded their interview study in a standardized 
protocol for acceding to HR requests, focused on empowering women to make autonomous decisions. They reported on findings from 82 women attending two or more clinic visits, $48 \%$ of whom reported being victims of sexual violence, and 24 of whom ultimately opted for the operation. (Of those, 19 were available for follow-up, though only two reported bleeding during first post-operative intercourse.)

Loeber et al. reported results from 154 women seeking advice for virginity-related issues ( $29 \%$ of whom had suffered forced intercourse and/or incest), of whom less than half opted for surgery. Of these, 48 chose HR, and 26 temporary hymen suture (THS). At follow-up, 13 of the 17 women who had THS, and six of the 11 who had HR, reported blood loss on their wedding night; by comparison, all six women of the women in the study who opted to insert a capsule containing food coloring reported stained sheets.

Our research contributes to the limited empirical evidence on HR through a narrative analysis of interviews with 15 participants: 1.) six women who sought HR; 2.) four individuals who accompanied such patients; and 3.) five health care professionals (HCPs). Our aim was to focus on women's own understanding of what they were doing and why. We were inspired to counteract the appropriation of women's voices apparent in much of the bioethical and empirical literature on HR, as well as the simplistic and reductive interpretation of HR as a "quintessential sign of women's unfreedom" (AbuLughod, 2002:786). A focus on women's own voices - and HCPs wanting to help such patients - will enrich the debate on HR. Such a focus may well be the most important necessary corrective to a normative discussion that is at risk of becoming polarized around two insufficiently reflective positions: one that refuses to conscientiously engage with the moral and social dimensions of HR (e.g. Tschudin et al 2013, Essén et al 2010, on the lack of professional guidelines, and on how some requesting women have simply been turned away), and another that advocates policies and professional recommendations that reject the practice without exception (e.g. Juth \& Lynöe 2014 on 
Swedish zero-tolerance). Both of these are unhelpful starting points, with the latter position condemned as a form of cultural imperialism (Saharso 2003:209-10).

Instead, we draw from work in social and cultural anthropology that highlights how women use medicine pragmatically for their own benefit (Lock \& Kaufert 1998). This helps us to avoid the twin pitfalls of normative under- and over-reaction: moral relativism on the one hand and victim-blaming on the other (Zigon 2008). Lock and Kaufert argue that women, rather than being passive recipients of medicine, actively and realistically evaluate medical options in light of their personal, social, and economic circumstances. On this account, women then tend to make choices that assist them to pursue their goals and independence: "If the apparent benefits outweigh the costs to themselves, and if technology serves their own ends, then most women will avail themselves to what is offered" (1998:7). Although Lock and Kaufert do not explicitly discuss HR, we argue that their perspective allows for an analysis of women seeking HR that neither begins nor ends by condemning them for their actions or choices about their own bodies.

\section{Setting}

This study was conducted in and around Tunis, Tunisia's capital. Tunisia's total population is nearly 11 million (International Institute of Statistics 2014), 99\% of whom are Sunni Muslim (US Department of State 2013). In 2012, $29.9 \%$ of women had a secondary or higher level of education (compared to $44.4 \%$ of men) and $25,5 \%$ worked (versus $70 \%$ of men) (Human Development Report 2013).

The story of women's rights in Tunisia is characterized by a strong secular movement in support of gender equality, despite an enduring socio-political reality of conservative, patriarchal norms. Habib Bourgiba, the first Tunisian president after the French protectorate (1881-1956), was, despite otherwise repressive and autocratic 
politics, demonstrably committed to securing women's rights. He oversaw the creation of a secular state that fostered gender equality to a greater extent than many MENA countries, including legally recognizing, in 1973, women's right to free, anonymous abortion services without restriction as to reason or marital status (Murphy 2003, Brandt \& Kaplan 1995). Zine al-Abidini Ben Ali, who seized power in a coup in 1987, continued to promote women's rights, although this occasionally conflicted with the country's economic liberalization plans and with politically powerful Islamic conservative movements (Murphy 2003:170). Ben Ali's strategy to weaken Islamist and communist movements, for example, led to the arbitrary arrest and torture of hundreds of women (Amnesty International 1993), and gender discrimination and violence against women would remain prevalent (Brandt \& Kaplan 1995, Murphy 2003:182).

Tunisia, like many MENA region countries, is currently undergoing significant social and demographic changes — fuelled by globalization, urbanization, delayed marriage age, foreign travel and access to social media, as well as by population expansion and unemployment — which have also helped to coalesce diverse women's movements in the continued struggle for gender equality (Ehrhardt et al. 2009, Johansson-Nogués 2013). On one hand, never before have so many Tunisian women demanded recognition of their rights and openly questioned social norms that demean and subjugate them, including virginity before marriage (Ehrhardt et al. 2009). On the other hand, increasing rates of violence against women raise concerns that hard-won achievements may be in the process of being undone (Tchaicha and Arfoui 2012; Kelly \& Breslin 2010; Johansson-Nogués 2013).

\section{Methods}

Our study was designed to generate qualitative data in a MENA context to answer one seemingly simple question: What do women seeking HR, and the individuals supporting 
them, think about the procedure? The study received ethical approval from the National Tunisian Ethics Council.

\section{Pilot study}

In order to test the appropriate method, we collaborated with a bilingual French and Arabic-speaking sociologist (xx) living in Tunisia to first conduct 13 semi-structured or structured pilot interviews in 2008 in Tunis. We also tested different survey formats with women who underwent the operation, as well as their friends, nurses, physicians, students, academics, and women's rights activists. The pilot study results (unpublished) revealed the practice to be widely known as available in Tunisia. Most participants regarded HR - even the mere mention of it — to be socially taboo. Some openness to discussion of HR was found among feminist and human rights activists, but most pilot interviewees felt uneasy about participating, particularly women who had undergone the procedure. We found that structured interviews or surveys seemed to be too intrusive and unlikely to result in meaningful data, and that it was paramount to first build trusting relationships between researcher and the respondent.

In light of the pilot findings, we ruled out further use of structured interviews or surveys. An exploratory qualitative interview study with semi-structured interviews was employed instead, so as to feasibly but with sensitivity solicit and explore more deeply the personal, social, and moral complexities of HR requests revealed in our pilot interviews (Strauss \& Corbin 1998; Yin 2003). This facilitated greater researcher reflexivity, particularly important for understudied phenomena that are deeply embedded in historical, social, and cultural norms and values, like HR.

\section{Semi-structured interviews}


The interview team included xx and a Tunisian psychologist. Participants' informed consent was difficult to obtain; in many cases, several weeks and multiple conversations were needed to establish relationships sufficiently trusting to secure consent for an actual interview during which recording or note-taking was allowed.

Among the participants, all recruited through a snowball technique, were six women (four who had undergone HR, one who was seeking it, and one whom the research team accompanied before, during and after the procedure), and nine otherwise involved persons: four physicians (three male, one female), one midwife, and four companions (three female, one male). Interviews were conducted mainly in a combination of French and Arabic. If the interviewees agreed, conversations were recorded on tape, then transcribed verbatim, with Arabic content translated into French; the excerpts included in this paper have been translated into English by the research team. If consent to record was denied, conversations were reconstructed following the meeting from notes taken during the encounter. Analogue tapes were stored and protected in Switzerland. Written transcripts and other notes were anonymized and kept secure by each member of the research group. All subject names in this paper are pseudonyms.

\section{Data Analysis}

We employed coding triangulation to decrease investigator bias in the data analysis (Miles \& Huberman 1994; Yin 2003). Four researchers (two bioethicists, one sociologist, one anthropologist) each analyzed the data separately to 1.) identify main cross-cutting themes, and 2.) summarize individual stories. To avoid selectivity bias, as many themes as were identified were included. Differing interpretations were discussed and resolved in group meetings and all of the material was then analysed by an external researcher (a qualitative research expert). Data analysis was conducted using the constant comparative approach developed by Glaser and Strauss (1967) and until saturations (no 
new topics emerged). The results include both common themes and story summaries, both presented here to limit the possibility of identifying any individual participant.

\section{Findings}

Health Care Professional and Companion interviews (Physicians $=$ Ph, Midwife $=M$, both groups $=\mathrm{HCP}$, Companions $=$ C)

The medical procedure

HCPs noted that HR became available in Tunisia in the 1970's, and that the typical patient today is 20-36 years old, with a rural or lower social class peri-urban background (although middle-class women in urban Tunis appear to be increasingly seeking HR), and accompanied by a female cousin or friend. HCPs reported that HR requests peak prior to the summer marriage season. Local or general anaesthesia was decided case by case, but general anaesthesia was favoured due to patient nervousness. Physicians reported discussing HR surgical techniques with colleagues, but, given the absence of clinical guidelines, performing the procedure the way they thought best. Two physicians suggested that most of their patients had both limited knowledge of reproductive anatomy and limited desire for details about the procedure and risks $(\mathrm{Ph} 2, \mathrm{Ph} 4)$.

The HCP interviewees noted that no legal or religious guidance on HR exists in Tunisia, and that there is no formal political debate about it either, even though “everybody knows it’s being done” (quote $\mathrm{Ph} 3$ ), and public authorities were simply playing "ostrich politics" (Ph1) (refusing to acknowledge the issue). Physician motivations to perform HR were reported to be mainly financial (remuneration per procedure is around 200 - 600 Dinars, approximately a school teacher's monthly salary), but also deontological (driven by professional obligation to prevent harm and do good in a wider than simply medical sense). 


\section{Ambivalent moral assessment}

Physicians were ambivalent in their moral assessment of HR. One called it a "farce" (Ph3); another called it "nonsense" and "hypocrisy", though then went on to emphasize the importance of being non-judgmental: "Physicians shouldn't be involved with a moral plan, nor judge" $(\mathrm{Ph} 2)$. One physician $(\mathrm{Ph} 3)$ claimed to have no moral problem with HR, but that women with "bizarre" requests should be discouraged from undergoing the procedure, as for example when sexual intercourse was already taking place with the future husband. One claimed that other physicians view HR as immoral and refuse to perform it (Ph4). The same physician, despite claiming to hold a neutral personal stance ("Ideologically I have nothing against [it][...]. The primary aim of medicine is to help"), later clearly expressed that only some women are deserving of HR based on their sexual histories: "I heard histories of violence $[\ldots]$ at the examination I see that they don't lie. In that case I perform the operation [...]. When I see that they simply want to hide something, I do not agree performing the operation."

\section{Patriarchal societal pressures to be a virgin bride}

Many of the HCPs and companions felt the emergence and availability of HR to be related to patriarchal repression of women. The physicians reported that women are motivated to seek HR through a combination of guilt related to personal reputation, family honour, and social pressure, especially from in-laws and future husbands. Such pressures generated anxiety for women before and during the procedure $(\mathrm{Ph} 2)$. Two physicians confirmed the findings from prior studies (Van Moorst et al. 2012; Loeber 2015) that many women seeking HR had previously been victims of sexual violence (Ph3, Ph4). One physician explicitly characterized HR itself as a form of patriarchal oppression, not entirely dissimilar to other forms of gender based violence, in that it amounts to a "reduction" of and "assault" on individual women $(\mathrm{Ph} 2)$. One companion 
(C2) came to a comparable conclusion: "If a woman asked me once more [...]. I would talk to her. I would say it is a violation to your body and your dignity.”

The reflections of a young humanities instructor (C3) who had supported three friends undergoing HR echo these views of HR as itself an oppressive violation of women's physical integrity. C3's impression was that all three friends emerged from their surgeries with more "maturity and wisdom", but also with more sadness, and having become "less open and radiant". C3 decried Tunisian society as "fanatic and macho", empowering only men, and argued forcefully that HR is a violation of women's rights: “There is a clear contradiction between women's rights and the HR. HR is coercion, it reduces $[\ldots]$ women's rights, it means $[\ldots]$ women have no right over their bodies. Doing this operation out of coercion and having rights is not possible, it's the society that coerces."

$\mathrm{C} 1$, who helped a cousin soon to be wed in an arranged marriage get into contact with a surgeon willing to perform HR, was similarly blunt about how patriarchal virginity norms function to create gender injustice, and emphasized the harmfulness of men's mistreatment of women and expectations of potential brides:

"I have many friends who were honest about their lost virginity. All the men refused to marry them. They want to sleep with no matter whom, even with prostitutes. But for the marriage they want a virgin. That affects almost the entire society."

\section{Companion/collateral trauma of $H R$}

All three companion interviewees who accompanied others to the surgery reported feeling anxious about the clinic visits and the HR. C1 was very nervous about the interview with us and whether anonymity would be ensured. She claimed to have been more afraid than her friend undergoing surgery. $\mathrm{C} 2$ described being asked by her friend 
Z, a lawyer facing an arranged marriage, to secretly accompany her for an HR several days in advance of Z's wedding. C2 asked why Z was marrying such a conservative man after having thus far lived a rather liberal life. $\mathrm{Z}$ replied that she had reached "a certain age", indicating to $\mathrm{C} 2$ that $\mathrm{Z}$ felt she was facing perhaps her last chance to marry and bear children. $\mathrm{C} 2$ went on to describe the operation as a form of bodily aggression and experienced witnessing it as an emotional hardship:

"I was completely torn, because I am against this operation. I cannot accept it. I only did it as a favour for my friend [...]. There is a societal pressure that is responsible for her accepting the operation [...]. It is an aggression against her, a damage of her physical and sexual intimacy. Afterwards, when we were both sitting in the car, I lost my nerves. I freaked out. I told her that I could not see her suffering anymore. She cried. It struck me tremendously [...]. She said: 'If not, I cannot marry. But I want to have children, I want to marry.' [...] I called her the morning [of her wedding] on her cell phone. She was in the hotel, she was so content, she was so relieved, she was so happy."

Being unable to tolerate being in the same building where such an aggression was being committed for the sake of a "macho who wanted a virgin", C2 had left the hospital while waiting for $\mathrm{Z}$ to be operated. The friends never again spoke of the operation. $\mathrm{C} 2$ claimed to be even more frightened than $\mathrm{Z}$ during the wedding ceremony and admitted to lasting trauma — "The whole thing was very painful for me" — even though she reported that Z was now living a happy life with children and did not doubt her marriage.

\section{Women undergoing the surgery}

\section{General findings}

Most of the women interviewees had lower or middle class socio-economic backgrounds and, apart from one who was unemployed, were either employed or were pursuing their 
educations. Most mentioned intense social pressure to be a virgin, but few explicitly employed any language related to gender injustice, women's rights, or HR as a violation of physical integrity. Four women (Ana, Bea, Celina, Dina) felt that the decision to undergo HR was a decisive moment in their lives, on which important issues depended, including the ability to start a family and to reconcile the lives they had experienced in the past with the lives they wanted to live in the future. The women all paid for their procedures themselves, and all perceived the amount to be onerously high.

For Elena, the operation enabled a desired future by covering up an undesirable past. For her, the operation was about complicity with her surgeon to conceal prior sexual relationships and to thereby protect her from harmful consequences. Fahra revealed yet another primary motivation for seeking HR: the operation was for her a step toward leading a more self-determined life. A summary of the rich interview material is presented below, organized according to four overarching themes.

\section{[1.] Anxious decision for HR as the sole option to live the desired life}

Four women reported that social pressure drove them to seek HR. These women viewed HR as their sole option to get married and have children. They also all reported feeling uncertain and anxious prior to undergoing HR, as well as immense relief with their subsequent weddings and marriages.

Ana had lost her virginity to her first fiancé. He had violently inserted his hand into her vagina, telling her he wanted to see whether she would bleed. He then blackmailed her into further sexual relations by threatening to expose her for no longer being a virgin. Fear about not bleeding during intercourse engulfed Ana in the lead up to an arranged marriage with a second fiancé, so she sought HR. : "After the operation, it hurt very much, I could not move. I was scared when I saw the blood, but I could not cry. 
On the day of my marriage, we drove $120 \mathrm{~km}$ by car to do the operation [...]. I had no joy. I was not really present at my wedding."

Ana afterwards described feeling relieved, and expressed no regret about her operation and her marriage, although she retained some ambivalence about the experience: "I do not approve this operation, but in my case, how should I have done it without?"

Bea, who agreed to marriage just one month before being wed and was hesitant about committing to a fiancé who wanted a virgin bride, expressed similar feelings: "It was not easy. I did not know what I was supposed to think about: the marriage, the risk, if it [HR] would work [...]. I needed a friend to drive me [...]. I felt bad, I was scared. I remember everything very well right before the operation [...]. Afterwards I was confused, $[\ldots]$ and there was the stress of marriage." Bea was one of the few women to explicitly draw a direct link between social pressure and gender injustice: "Society is cruel with women, it does not accept them easily. [...] A man can choose whatever girl he likes". She, like Ana, disapproved of the operation, but felt there was no alternative: "I had the problem of age, I really wanted children. This was the opportunity." She described her wedding night, and her fear that the HR would be obvious because the sutures would be visible to her husband: "I was terrified [...]. He was very gentle. It all went well. He got up and went to the bathroom. I could not think of anything other than the [surgical] sutures, but I did not find anything." Bea nonetheless expressed relief after HR and emphasized her happiness with life as a wife and mother. She felt no regret about her decision.

All three women felt strong pressure prior to marriage to be something other than what they felt themselves to be, and all lived in fear of the consequences of being found somehow despoiled or inadequate. In order to secure the social acceptance necessary for a strongly personally desired life as married with children, all three women perceived HR 
as their only salvation, despite never questioning the supposed link between virginity and an "intact" or "mended" hymen.

\section{[2.] The perceived crucial importance of $H R$}

Dina described suffering from fear and pressures similar to the previous three women, and she also experienced relief following HR, despite parting ways with the others by indicating that she would never undergo the procedure again. Interviewed on seven occasions, Dina was the only participant to undergo HR during the course of this research, which lends her insights both more immediacy and may make them more reliable.

Dina reported that all her friends were getting married and that she too had begun to receive marriage proposals. Stressing that she had not suffered sexual violence (she was "never touched", and "never deceived anyone"), but remembering bleeding as a child, Dina sought a physician's confirmation that her hymen was intact, and thus her virginity. She was in despair when her physician told her that her hymen was not intact: "In that moment, I fell, I fainted. I was shocked. I vomited. It crushed me." Like the other women, she seemed not to question the lack of connection between hymeneal tissue, virginity, and blood on the wedding bed sheets. Indeed, Dina felt burdened by a devastating secret that had to be hidden and which had led her to refuse several proposals prior to agreeing to an arranged marriage. Dina had not and was not to meet her fiancé prior to their wedding and did not know whether he insisted on marrying a virgin. Like most other women we interviewed she expressed feeling that realizing the life she wanted for herself depended crucially on her undergoing HR: "It can fix everything, and it can destroy everything."

Dina reported that a variety of major life decisions - about whom and when to marry, and what jobs to take for how long — depended on when and whether to undergo 
the surgery. Until she earned enough to pay for the procedure, she kept turning down offers of marriage: "I started working because I knew I was not a virgin [and needed to pay for the surgery]." She thought only of her wedding night and not beyond: her future married life and the level of intimacy were unimportant.

The day of her procedure, two members of our team accompanied Dina, but waited outside the surgical theatre, rejoining her afterwards in recovery. Emerging from general anaesthesia, Dina wanted to tell the surgeon that no man had ever touched her. She also indicated strong pain in her vagina. The midwife explained how to take care of the wound, telling Dina: “The story is over". After her postoperative appointment, Dina was relieved to be told she was healing properly — she had feared that she had been too active and as a result jeopardized the success of the operation - and finally felt able to think about the future: "Now I am more relaxed. I am starting to think. Now I am starting to feel that I am going to be married." She also claimed however that if ever [HR] did not work" she would not undergo the procedure again: "it was a mistake", "it was too stressful."

\section{[3.] The complicit physician}

Elenya seemed to be under less social pressure than the other women, though she did not speak as openly about her feelings. She did spoke openly about her sexual experiences and previous abortions. Her interview took place prior to her HR, but no follow-up was possible. Her story nonetheless illustrates more than the others how physicians can assist in concealing past sexual activity. Elenya was under 18 when she first had sex, with a married man almost 30 years her senior:

"He took advantage of my trust and from the fact that I was young [...]. He did a penetration, he deflowered me. I said, what is that? He said it's the rest of your menstruation." 
Another man later attempted to blackmail Elenya for sex; when she refused, he contacted her parents and informed them she was no longer a virgin. Elenya reported that they made her swear to the contrary. Elenya then had further relations with other men, and three abortions followed, performed by the same physician, and paid for by Elenya from her own earnings. Elenya apparently carried one pregnancy up to the fifth month and then had a "mini-caesarean [section]", as she put it. Her physician helped her cover up that surgery, and reassured her parents that Elenya was still a virgin. He warned Elenya that her mother was highly suspicious however, and provided contraception information.

At the time of her interview Elenya reported being sexually active with her fiancé, though they were abstaining from vaginal penetration. As her marriage approached, Elenya asked her physician for "a solution, something that I can do". The physician explained the possibility to reconstruct her hymen with a laser. Elenya understood this to be the surest option in light of her fear, identical to Bea's, that the HR sutures would be visible to her husband.

\section{[4.] HR as an attempt to recover from sexual violence}

Farah differed from the other women in her explicitly expressed independence from societal expectations. She had undergone HR four years prior to her interview. She agreed to be interviewed in her explicit interest of contributing to social change, to make her voice heard: "I want to [bear] witness, so that the people know, so that the mentality changes and so that the girls do not have to lie anymore." Farah had endured an extremely violent first sexual contact — which she called a "disaster" and a "black spot" — and very nearly died from the resulting internal bleeding. She later fell in love with a man whom she believed held progressive views - they drank alcohol together socially, for example — and they enjoyed dating each other for three years while refraining from sexual intercourse. When they decided to marry, Farah expressed a desire to ensure a 
"pleasurable first time" for them both and underwent HR: "When I did the operation I said, first it's for me, second for him. To please him, since I love him so much. And he loved me.” Her wedding night was satisfying, altogether different from her first sexual experience. She was initially very satisfied with her decision to undergo HR: "I did not think of the perspective of my fiancé [...]. I wanted to have a first time with someone who is not brutal, who is not forceful."

Three weeks into the marriage, a happy and confident Farah confided in her husband her full sexual past, including her rape and HR. He later demanded a divorce, on the basis of her lack of truthfulness about her past. "Then there was violence", she reported. At the divorce proceedings, Farah requested nothing from her husband. Three years later, she had paid for her education, earned a diploma, and was unmarried but in a rewarding relationship. Farah was eager to be interviewed in order to discourage other women from undergoing HR and to encourage them to accept only men who accept them as they are and to be fully honest about their past prior to getting married

\section{Discussion}

Our findings show that there was a great deal at stake for the women seeking HR we interviewed, notably their prospects for dignified, socially integrated, happy, and fulfilled lives as married women and mothers. The women were looking to HR to help them accommodate their various selves across time: they sought to avail themselves of a discreet medical procedure that seemingly permitted the integration of their past lives with their desired futures. Strong social pressures generated fear, and motivated most women to conceal both sexual activity prior to marriage and the procedure of hymen repair itself. In most cases, a striving to meet the expectation to seem a virgin at marriage framed the women's desires and directed their decision-making: they wanted a family and could envisage achieving that only by undergoing HR. The operation resulted in 
physical discomfort for some but also frequently produced considerable psychological relief. Those whom we interviewed after the fact, and who did not disclose their HR to their spouses, reported being satisfied both with their decisions and the lives those decisions helped to bring about.

Farah was the exception: seemingly free from pre-marriage pressures or fears, she sought HR to insure a mutually pleasurable first sexual experience with her husband, in contrast to the violence of her prior experience. She demonstrated greater independence than the other women interviewed: choosing to undergo the operation alone, for example, insisting the reconstruction was primarily for herself, and choosing to disclose her history to her husband. In retrospect she was also not unhappy about her divorce. Furthermore, she pursued her education, and entered into relationships that made her comfortable and satisfied, and in which her partner respected her regardless of her past. It was clear however, that she also hoped for a change of "mentality" such that women would not have to opt for HR.

Most of the women interviewed had experienced sexual coercion, if not outright criminal violations of their bodies. Although they reported being victimized and exploited by men, they did not view HR as similar to such assaults, in marked contrast to the HCPs and companions. None of the women argued that HR be outlawed: recourse to HR was a way of lessening the burden of restrictive, oppressive and unfair social norms. HR reconstructed more than a piece of vaginal tissue: it reconstructed the option to have a desired life within a social context that demands virginity before marriage, and thus might be interpreted as a form of empowerment. As Lock and Kaufert argue in their analysis of women's tendency toward pragmatism in medical decision-making, choosing HR can be interpreted here as reclaiming a certain degree of agency and autonomy (Lock \& Kaufert 1998:1). 
In stark contrast, HCPs and companions characterized HR as morally questionable; they were far more critical of HR than were the women who actually underwent surgery, and felt far more ambivalence about the proliferation of the practice. It is no simple matter, however, to separate criticism of societal circumstances driving HR demand, as opposed to personal choice to undergo it. For example, the companion who argued that HR reduces women's rights spoke at more length about the operation in general rather than in specific circumstances faced by individual women. Similarly, most physicians and companions felt that patriarchal societal structures, gender inequity, and the "virginity rule", were the fundamental problems, and that HR is a somewhat dubious personal response.

These results complement the other two studies that engaged women about their HR (Van Moorst et al. 2012, Loeber 2015). We agree with their core recommendations: the clearest need, and the clearest medical duty, is to provide women considering HR with knowledge of their own anatomy, including sexual and reproductive health information, so that they understand both how many cultural beliefs about virginity are biologically false and misleading, and how limited are the prospects for "reconstructing virginity" surgically. To impart such understandings, we further agree with both studies that HCPs would do well to consider integrating a multiple visit, counseling-based empowerment approach (Van Moorst et al. 2012) that seeks to discourage women from undergoing HR by better informing them of their options, but does not deny them recourse to the procedure if they absolutely and with full information decide that it is in their best interests.

Such an approach may help HCPs avoid falling into the trap, altogether too common in both bioethical and anthropological debates, of reducing women to being "near automatons" of enculturated social norms (Cook 1999). Following Sawicki (1991) and Little (1998), we reject the view that a liberal feminist commitment to criticize 
oppressive social norms, as well as the individual choices that sustain them, rules out sympathy for those who are victimized by such norms. Instead, we suggest that women seeking HR are both victims and agents: they cannot realistically hope to be completely free of coercive patriarchal attempts to control their bodies, but they may resist such attempts by seeking HR.

The aim of this paper is not to pass judgment either on women's choices to avail themselves of HR in light of the cultural pressures they face, nor on those who facilitate such choices. The results presented here suggest a more complex reality surrounding these choices and practices, similar to recent turns in the debate about female genital mutilation/cutting (Gruenbaum 2001), whereby more nuanced ethical analyses is emerging that acknowledges the genuine harms at stake, but does not suffer from being based on cultural or moral double standards (Earp 2015). This research thus contributes to a deepening of the medical and normative ethical debate surrounding HR, and suggests that crafting legitimate policy and regulatory responses to demand for the procedure will require greater sensitivity to social context, and to individual women's reasoning and moral trade-offs, than has thus far appeared in the literature.

\section{Strengths and limitations of the study}

The strength of this study is that it gives voice to women targeted by the availability of HR in an understudied region where virginity norms predominate. The major limitations are low recruitment results (withdrawal of formal informed consent was common, mainly due to concerns about anonymity, the recording of interviews, and the taboo subject matter) and the inability to follow-up with interviewees. Another limitation is the retrospective nature of most of the interviews.

While we believe that political upheaval beyond our control is largely what discouraged recruitment and prevented study continuation, we view our results as 
nonetheless unique, and our analysis sensitive, rigorous and novel. The sensitive qualitative approach, focused on establishing trusting relationships, enabled data capture revealing a deeper understanding of beliefs and motivations than has been previously published.

\section{Conclusion}

This paper presents empirical findings related to an ethically controversial and understudied medical procedure that appears to be increasingly globally prevalent, though largely in private and only loosely regulated in some clinics. Although HR appears to be a relatively minor medical intervention, many women who seek it do so because they find themselves in physically and socially precarious, even dangerous, circumstances. Physicians who perform the intervention must navigate not only the moral ambiguity surrounding the justifiability of HR in general and for specific women, but also clinical and legal ambiguity given that the practice is subject to few professional guidelines or standards, and generally performed in secrecy.

We found that some women see HR as a form of salvation, compromise, and accommodation: a medical technology that promotes a degree of autonomy for them within communities intolerant of deviance from convention. In this sense, HR can be beneficial for women (if largely as a psychologically beneficial resource rather than a physically necessary surgery) who do not wish or feel they can safely extricate themselves from patriarchal communities that insist upon the norm of female virginity before marriage.

The primary aim of this paper is not to propose a detailed normative position on how health professionals ought to act faced with requests for HR - and many questions remain for further discussion -, but to present empirical evidence relevant to the understanding of demand for HR. 
Two preliminary normative conclusions nonetheless clearly emerge from this research. The first is that many women seek HR because of highly fraught personal situations, and medical practitioners must thus take time to listen to them, to educate them about human anatomy, and to support improvements in sexual and reproductive health education more generally. The second is that much of the moral unease surrounding HR is quite trivial compared to the fundamental problems of persistent gender inequity and sexual violence, and intense societal pressure on women to refrain from sexual activity prior to marriage, both of which are deeply embedded in a complex web of traditional gendered practices, religious beliefs and politics. There is already ample evidence that patriarchal norms create coercive environments for women; we found that such environments impose on some Tunisian women feelings of shame, solitude, and secrecy, and also drive some of them to seek medically unnecessary surgery. An analysis of our data from the standpoint of moral pragmatism, as suggested by Lock and Kaufert (1998), suggests that recourse to HR as an alleviating resource under the current circumstances will not likely abate before improvements in gender justice and women's autonomy are achieved. 


\section{References}

Abu-Lughod L. Do Muslim Women Really Need Saving? Anthropological Reflections on Cultural Relativism and Its Others. American Anthropologist. 2002;104(3):783-90.

Adams JA, Botash AS, Kellogg N. Differences in hymenal morphology between adolescent girls with and without a history of consensual sexual intercourse. Arch Pediatr Adolesc Med. 2004;158(3):280-285.

Ahmadi A. Ethical issues in hymenoplasty: views from Tehran's physicians. J Med Ethics. 2014;40(6):42930 .

Ahmadi A. Recreating Virginity in Iran: Hymenoplasty as a Form of Resistance. Medical Anthropology Quarterly 2015;doi:10.1111/maq.12202

Amnesty International. Tunisie. Des femmes sont victimes de harcèlement, de torture et d'emprisonnement. MDE. 2 June 1993

Amy J-J. Certificates of virginity and reconstruction of the hymen. Eur J Contracept Reprod Health Care.2008;13(2):111-3.

Awwad J, Nassar A, Usta I, Shaya M, Younes Z, Ghazeeri G. Attitudes of Lebanese university students towards surgical hymen reconstruction. Arch Sex Behav.2013;42(8):1627-35.

Bekker M, Rademakers J, Mouthan I, \& De Neefe, M. Reconstructing Hymens or Constructing Sexual Inequality? Service Provision to Islamic Young Women Coping with the Demand to be a Virgin. Journal of Community \& Applied Social Psychology.1996;6(5):329-334.

Boddy J. Wombs and Alien Spirits: Women, Men, and the Zar Cult in Northern Sudan. Univ of Wisconsin Press; 1989.

Bordo S. Unbearable Weight: Feminism, Western Culture and the Body. Berkeley, CA: University of California Press; 1993.

Brandt M, Kaplan JA. The Tension between Women's Rights and Religious Rights: Reservations to Cedaw by Egypt, Bangladesh and Tunisia. Journal of Law and Religion.1995;12(1):105.

Braun V. Female genital cosmetic surgery: a critical review of current knowledge and contemporary debates. J Womens Health (Larchmt).2010;19(7):1393-407.

Brock DW. Conscientious refusal by physicians and pharmacists: who is obligated to do what, and why? Theor Med Bioeth.2008;29(3):187-200.doi: 10.1007/s11017-008-9076-y.

Butler J. Bodies that Matter: On the Discursive Limits of Sex. London: Routledge;1993.

Butler J. Undoing Gender. New York: Routledge;2004.

Chambers C. Autonomy and equality in cultural perspective Response to Sawitri Saharso. Feminist Theory.2004;5(3):329-32.

Cook JW. Morality and Cultural Differences. Oxford: Oxford University Press;1999.

Cook RJ, Dickens BM. Hymen reconstruction: ethical and legal issues. Int J Gynaecol Obstet.2009;107(3):266-9. 
Earp BD. Hymen "restoration" in cultures of oppression: how can physicians promote individual patient welfare without becoming complicit in the perpetuation of unjust social norms? J Med

Ethics.2014;40(6):431.

Earp BD (under review). Between moral relativism and moral hypocrisy: the case of 'FGM.' https://www.academia.edu/10197867/Between_moral_relativism_and_m oral hypocrisy The case of FGM.Last accessed 25/06/2015

Ehrhardt AA, Sawires S, McGovern T, Peacock D, and Weston M. Gender, Empowerment, and Health: What Is It? How Does It Work?. Journal of Acquired Immune Deficiency Syndromes. 2009;51(3):S96105.doi:10.1097/QAI.0b013e3181aafd54.

Essén B, Blomkvist A, Helström L, Johnsdotter S. The experience and responses of Swedish health professionals to patients requesting virginity restoration (hymen repair). Reprod Health Matters.2010;18(35):38-46.

Gay-Y-Blasco P. A `Different' Body? Desire and Virginity Among Gitanos. The Journal of the Royal Anthropological Institute.1997;3(3):517-35.

Glaser BG, Strauss AL. The Discovery Of Grounded Theory: Strategies for Qualitative Research. New York: Aldine de Gruter; 1967.

Goodman MP. Female genital cosmetic and plastic surgery: a review. J Sex Med.2011.8, 1813-1825. doi:10.1111/j.1743-6109.2011.02254.x

Grosz E. Volatile Bodies: Towards a Corporeal Feminism. London: Routledge;1994.

Grosz E. Time Travels: Feminism, Nature, Power (Next Wave). Durham: Duke University Press;2005.

Gruenbaum E. The Female Circumcision Controversy: An Anthropological Perspective. University of Pennsylvania Press;2001

Human Development Report 2013. Tunisia. http://hdr.undp.org/sites/default/files/Country-Profiles/TUN.pdf, p 4).Last accessed 9/9/2014

International Institute of Statistics. Tunisia. http://www.ins.nat.tn/indexen.php. Last accessed 9/9/2014

Johansson-Nogués, Elisabeth. Gendering the Arab Spring? Rights and (in)security of Tunisian, Egyptian and Libyan Women. Security Dialogue 2013;44(5-6):393-409.doi:10.1177/0967010613499784.

Juth N, Lynöe N. Zero Tolerance against Patriarchal Norms? A Cross-Sectional Study of Swedish Physicians' Attitudes towards Young Females Requesting Virginity Certificates or Hymen Restoration. Journal of Medical Ethics.2014.medethics-2013-101675.doi:10.1136/medethics-2013-101675.

Juth N, Tännsjö T, Hansson S-O, Lynöe N. Honour-related threats and human rights: a qualitative study of Swedish healthcare providers' attitudes towards young women requesting a virginity certificate or hymen reconstruction. Eur J Contracept Reprod Health Care.2013;18(6):451-9.

Kelly S, Breslin J. Women's Rights in the Middle East and North Africa: Progress Amid Resistance. Rowman \& Littlefield Publishers;2010.

Little MO. Cosmetic surgery, suspect norms, and the ethics of complicity. In Enhancing human traits: Ethical and social implications; ed. Erik Parens, 162-76. Washington, DC: Georgetown University Press;1998

Lock M, Kaufert PA. Pragmatic Women and Body Politics. Cambridge University Press;1998

Loeber O.Wrestling with the Hymen: Consultations and Practical Solutions. The European Journal of Contraception \& Reproductive Health Care 2015;20(2):128-35.doi:10.3109/13625187.2014.984834 
Logmans A, Verhoeff A, Raap RB, Creighton F, van Lent M. Should doctors reconstruct the vaginal introitus of adolescent girls to mimic the virginal state? Who wants the procedure and why. BMJ.1998;316(7129) 459-60.

Malmqvist E, Feiler K. Cultural norms, the phenomenology of incorporation, and the experience of having a child born with ambiguous sex. Social Theory and Practice, 2010,36 (1):133-56.

McDougall LJ. Towards a clean slit: how medicine and notions of normality are shaping female genital aesthetics. Culture, Health \& Sexuality 2013,15 (7):774-87.

Miles MB, \& Huberman AM. Qualitative data analysis: An expanded sourcebook (2nd ed.). Sage Publications: Thousand Oaks, CA;1994.

Murphy EC. Women in Tunisia. Between State Feminism and Economic Reform. In: Doumato EA, Posusney MP. Women and Globalization in the Arab Middle East: Gender, Economy, and Society. Boulder: Lynne Rienner Publishers; 2003.

Ou M-C, Lin C-C, Pang C-C, Ou D. A cerclage method for hymenoplasty. Taiwan J Obstet Gynecol.2008;47(3):355-6.

Prakash V. Hymenoplasty — how to do. Indian Journal of Surgery. 2. September 2009;71(4):221-3.

Raphael DD. Should doctors reconstruct the vaginal introitus of adolescent girls to mimic the virginal state? The ethical issue is deceit. BMJ.1998;316(7129):460

Saharso S. Feminist Ethics, Autonomy and the Politics of Multiculturalism. Feminist Theory. 2003;4(2):199215.

Sawicki, J. Disciplining Foucault: Feminism, Power, and the Body. Psychology Press;1991

Shildrick, M and Price J. Vital Signs: Feminist Reconfigurations of the Bio/logical Body, Edinburgh, Edinburgh University Press;1998.

Sissa, G. Greek Virginity. Cambridge, Mass: Harvard University Press;1990

Steinmüller H, Tan T. Like a virgin? Hymen restoration operations in contemporary China. Anthropology Today.2015;31(2):15-8.

Strauss A \& Corbin J. Basics of qualitative research: Techniques and procedures of developing grounded theory. Sage Publications: Thousand Oaks, CA;1998.

Tchaïcha JD, Arfaoui K. Tunisian women in the twenty-first century: past achievements and present uncertainties in the wake of the Jasmine Revolution. The Journal of North African Studies 2012;17(2):215 38.doi:10.1080/13629387.2011.630499.

Triana L, Robledo AM. Aesthetic surgery of female external genitalia. Aesthet Surg J. 2015 Feb;35(2):16577.doi:10.1093/asj/sju020.

Tschudin S, Schuster S, Dumont dos Santos D, Huang D, Bitzer J, Leeners B. Restoration of virginity: women's demand and health care providers' response in Switzerland. J Sex Med.2013;10(9):2334-42.

US Department of State. International Religious Freedom Report for 2013.

http://www.state.gov/j/drl/rls/irf/religiousfreedom/index.htm\#wrapper. Last accessed 9/9/2014

Van Moorst BR, van Lunsen RHW, van Dijken DKE, Salvatore CM. Backgrounds of women applying for hymen reconstruction, the effects of counselling on myths and misunderstandings about virginity, and the results of hymen reconstruction. Eur J Contracept Reprod Health Care.2012;17(2):93-105.

Wei SY, Li Q, Li SK, Zhou CD, Li FY, Zhou Y.A new surgical technique of hymenoplasty. Int J Gynaecol Obstet.2015;130(1):14-8.doi:10.1016/j.ijgo.2014.12.009. 
Wild V, Neuhaus-Bühler R, Poulin H, Brockes C, Schmidt-Weitmann S, Biller-Andorno N.Requests for online consultations on the operative reconstruction of the hymen--data from the university hospital Zurich and the children's hospital Zurich. PRAXIS.2010;99(8):475-80.

Yin RK. Case study research: Design and methods (3rd ed.). Sage Publications: Thousand Oaks, CA.;2003.

Zeyneloğlu S, Kisa S, Y1lmaz D. Turkish nursing students' knowledge and perceptions regarding virginity. Nurse Educ Today.2013;33(2):110-5.

Zigon J. Morality: An Anthropological Perspective. Oxford: Berg;2008 